\title{
A Linear Stochastic System Approach to Model Symptom Based Clinical Decision Support Tool for the Early Diagnosis for Psoriasis, Seborrheic Dermatitis, Rosacea and Chronic Dermatitis
}

\author{
İnci Zaim Gökbay ${ }^{\text {(D) }}$, Zeynep Beyza Zileli² (D), Pelin Sarı² (D), Türker Togay Aksoy³ (iD, \\ Sıddık Yarman ${ }^{4}$ (iD \\ 'Department of Informatics, İstanbul University, İstanbul, Turkey \\ Institue of Graduate Studies Science and Engineering, İstanbul University-Cerrahpaşa, İstanbul, Turkey \\ 3Department of Biomedical Device Technology, İstanbul Aydın University, İstanbul, Turkey \\ ${ }^{4}$ Department of Electrical and Electronics Engineering, İstanbul University-Cerrahpaşa, İstanbul, Turkey
}

Cite this article as: Zaim Gökbay I, Zileli ZB, Sarı P, Aksoy TT, Yarman S. A Linear Stochastic System Approach to Model Symptom Based Clinical Decision Support Tool for the Early Diagnosis for Psoriasis, Seborrheic Dermatitis, Rosacea and Chronic Dermatitis. Electrica, 2019; 19(1): 48-58.

\section{ABSTRACT}

Prediction models provide the probability of an event. These models can be used to predict disease's outcomes, reccurencies after treatments. This paper presents an expert system called Symptom Based Clinical Decision Support Tool (SBCDST) for early diagnosis of erythemato-squamous diseases incorporating decisions made by Bayesian classification algorithm. This tool enables family practitioners to differentiate four types of erythematosquamous diseases using clinical parameters obtained from a patient. In SBCDST, Psoriasis, Seborrheic Dermatitis, Rosacea and Chronic dermatitis diseases are described by means of well-classified set of attributes. Attributes are generated from the typical sign and symptoms of disorder. Based on our clinical results, tool yields 72\%, 93\%, 89\% and 95\% correct decisions on the selected dermatology diseases respectively. System proposed will provide the opportunity for early diagnosis for the patient and the expert medical doctor to take the necessary preventive measures to treat the disease; and avoid malpractice which may cause irreversible health damages.

Keywords: Clinical Decision Support Systems (CDSS), linear stochastic model, psoriasis, seborrheic dermatitis, rosacea and chronic dermatitis

\section{Corresponding Author:}

Inci Zaim Gökbay

E-mail:

inci.gokbay@istanbul.edu.tr

Received: 06.04 .2018

Accepted: 08.11 .2018

(c) Copyright 2019 by Electrica

Available online at

http://electrica.istanbul.edu.tr

DOI: 10.26650/electrica.2018.081118

\section{Introduction}

The diagnosis of erythemato-squamous diseases such as; psoriasis, seboreic dermatitis, lichen planus, pityriasis rosea, chronic dermatitis and pityriasis rubra pilaris is a difficult problem in dermatology [1]. Analyzing available information to determine the pathophysiologic explanation for a patient's symptoms is only one of the classic problems of diagnosis. But they all share the clinical features of erythema and scaling with very few differences [2]. In dermatological identification process, clinical information is at the forefront of the diagnostic process. A thorough history and total skin examination with emphasis on the duration, distribution, morphology and pattern of skin lesions are essential. Biopsy, patch testing and dermotoscopy examinations are also used to improve the quality of diagnosis.

Any computer program designed to help clinicians to make pre-diagnosis and also clinical decisions is called as clinical decision-support system. Intelligent decision support system can be based on various machine learning algorithms. Machine learning refers to how systems maps the learning process, which is often achieved by seeking and discovering patterns in data, or statistical pattern recognition.

Linear Discriminant Analysis [3, 4] is a well-known scheme for feature extraction and dimension reduction. It has been used widely in many applications. In this preliminary work, linear discriminant analysis is preferred to predict and built up a a reliable Symptom Based Clinical Decision Support Tool (SBCDST) that will be useful for the patients, for family physicians and internists to guide the patients to the dermatology expert is developed for psoriasis, seborrheic dermatitis, rosacea and chronic dermatitis. 


\section{Psoriasis}

Psoriasis is a primary dermal disease with chronic and recurrent properties and is widespread. It may be observed anywhere on the skin. It may affect the whole body; however, the severity of the disease differs from one individual to another. In some cases, the symptoms are local and observed in the form of plaques, whereas in other cases the symptoms may be observed in various body parts and cover large areas of the skin. The incidence of this widely common disease is between 1 to $3 \%$. For example the prevalence of psoriasis in India ranges from $0.5 \%$ to $1.5 \%, 4$ to $5.5 \%$ in Malaysia, 0.29 to $1.18 \%$ in Japan and $3.1 \%$ in Kuwait, and in China, including Hong Kong ranges from $0.2 \%$ to $1.5 \%$ [5]

The most common locations where the symptoms occur are the knees, elbows, waist, scalp and the genital area. The disease typically presents itself with a thin layer of white scales on top of clearly outlined red patches, however it may also present itself in the form of red patches only or with pinhead sized infectious pustules on top of the red patches. Psoriasis is a genetic disease common in the age group of 20 to 40 . As it is an inherited disease, if the parents have psoriasis, it is more likely that it will be observed in the child.

There are certain factors affecting the onset of the first attack or increasing the severity of the disease. The primary factors are physical and psychological stress, excessive exposure to sun and usage of certain drugs (pain killers, hormones, cortisone, antihypertensives). The psoriasis will be stable if the patient leads a comfortable life, avoids fatigue and consumes drugs as few as possible. One of the typical symptoms of psoriasis is that new psoriatic plaques are formed on itching or injured areas of the skin. This is known as "Koebner phenomenon" [6].

Psoriasis diagnosed based on clinical appearance may sometimes be confused with eczema or allergic dermal diseases. "Psoriasis Palmoplantaris" (psoriasis of hands and feet) is a local form of psoriasis presenting itself with blisters, cracked skin and desquamation [7].

Contrary to popular belief, chronic psoriasis is successfully cured however it may recur due to its chronic nature. The duration of and intervals between these recurrent attacks may differ between individuals [8-9].

\section{Seborrheic Dermatitis}

There are many kinds of skin disorders, seborrheic dermatitis is a kind of eczama. It is also known as seborrheic eczama. The name seborrheic dermatitis implies an oily inflammation of the skin where disease is much complex then the name given. Its most commonly seen on the scalp, nasolabial folds, ears, eyebrows and chest with complaints appearance of red, flaking, greasy areas of skin. Variations in seborrheic dermatitis clinical picture are common [10].
It may be seen in every age and gender. However, it is more frequently observed in infants, middle aged and elderly population. This kind of eczama is more common in people with oily skin. This dermal disease is caused by excessive oil secretion of the skin and it has a greater incidence in people with white complexion.

The first symptoms are itchy and red skin. Redness is accompanied by dandruff formation on the scalp, to a tiresome extent. In some cases, the skin gets disturbingly moistened and greasy. The dandruff formation on the scalp is excessive as if the skin was flaking. Minor acnes may form due to the disease itself or the irritation it causes. A yellow oil discharge stain may be formed as a result of significant moistening.

In $70 \%$ of the cases, a fungus species was found, this led to the idea that this disease is caused by or exacerbated by fungi though this has not been proven. The prevalance of seborrheic dermatitis is $1-5 \%$ in adults. This rate increases in three age groups: the first three months of infants, adolescense and ages between 40 and 60 . The onset of the disease is commonly after adolescense, and lasts for years while the severity decreases or increases throughout the years. It is most common among males and the 20-40 age group [11].

Although the cause of seborrheic dermatitis is not clearly understood, it is associated with the factors like yeast Malassezia, hormones (androgens), sebum levels and immune response. The disease may be exacerbated by drugs, climate changes including temperature and humidity rate, diet, atopy, changes in pressure, neurological issues, microangiopathic vascular changes, alcohol consumption, metabolic changes, fatigue, stress and defficiency of riboflavin, pyridoxine or biotin. It is clear that Sebum has a role in the manifestation of the disease. However, sebum levels or sebum secretion is not found to be elevated in patients with seborrheic dermatitis [11-13].

\section{Rosacea}

It is a dermal disease presenting itself on central area of the face such as nose, chin, forehead and cheeks; the onset of the disease consists of rash and paraesthesia, as the disease progresses it may cause permanent redness of skin, dilation of the blood vessels, skin edema and tissue vegetation. It is also known as adult acne or acne rosacea as the symptoms are similar, however it differs from adolescence acnes as it is not caused by the activity of fat glands. The cause of Rosacea is not clearly known, some of the affecting factors are, genetic tendency, infectious causes, envorinmental factors, psychogenic factors, natural immune system respectively.

Rosacea is observed mostly in fair-skinned, colored-eyed adults of 30 to 60 years of age. Though more common among women, its course is more severe in men. Rosacea is a slow progressing disease and consists of stages (exacerbations). It has four clinical stages: 
Stage 1: Relapsing paraesthesia and rash attacks on face,

Stage 2: The redness of central face area becomes permanent and obvious blood vessels form on nose and cheeks,

Stage 3: The redness on the face becomes darker and persistent, small, red swellings or pimples form on nose, cheeks, forehead and chin (diffrent from white or dark spots),

Stage 4: Burning eyes or continuous sensitiveness of the eyes (ocular rosacea) and development of a red, swelled nose (rhinophyma). The disease is often diagnosed based upon clinical findings and no biopsy is needed. There are no laboratuary findings spesific to the Rosacea diagnosis.

In $1 / 3$ of the patients, there is involvement of the eyes. In $20 \%$ of the patients, only the eyes are involved without the involvement of the skin. It is very difficult to diagnose the disease when the skin is not involved. Ocular involvement is not related to the presence nor the severity of dermal findings. The symptoms of ocular involvement are blepharitis, conjunctivitis, ceratitis, photophobia, watering of eyes, burning of eyes, episcleritis, iridocyclitis, chronic edema around eyes, widespread pain around eyes, and blurred vision. Therefore, all patients with Rosacea shoud have ocular examination [14].

\section{Chronic Dermatitis}

Atopic eczama (endogen eczama, atopic dermetitis) is a type of itchy, chronically relapsing dermatitis seen in atopic individuals. The two most common clinical findings of atopy are atopic eczama and allergic rhinitis. The insidence of atopic eczema have been increasing over the last years [8].

Atopic dermatitis is an itchy, chronic skin disease. It may be observed at any age, however in $90 \%$ of the cases, its onset is before 5 years of age and in $50 \%$ of these cases after the first two months of infant age. It is the most common dermal disease in children.

The insidence of the disease has increased after the second world war. The frequency of the disease is affected by industrialisation, urbanisation and climate changes. The insidence is $4.3 \%$ in $6-13$ age group and $8.1 \%$ in $10-11$ age group in our country.

The disease is developed as a result of interaction between envorinmental and genetic factors. Familial allergy is an important risk factor. The disease has a negative impact on the quality of life of patients of any age. The risk is three times more when both parents have allergy.

Clinical characteristics of atopic eczema and the course of the disease vary between infants, children and adults. In infants the symptoms are dark red patches and blisters on face and outer surfaces of arms and legs, as patients get older the skin gets thicker, rougher and darker. The symptoms are further observed on eye lids, skin folds of knees and elbows, and neck. The skin is dry and itchy at all stages. In 20 to $30 \%$ of the cases, skin lesions regress at the end of age two. Itchiness is the most significant finding. It gets worse towards the end of the day due to sweating and wool clothes.

The disease may be treated with topical medicine, oral drugs and sunlight (phototherapy) depending upon the severity and the surface area it covers, and the patient's age. If the disease is not treated, infections may arise [15-19].

\section{Multi-Dimensional Linear Stochastic Model}

A disease universe, $U_{\text {Skin-Diseases }}$, containing many subsets (all different types of skin disease sets) inside can be defined as shown Figure 1.

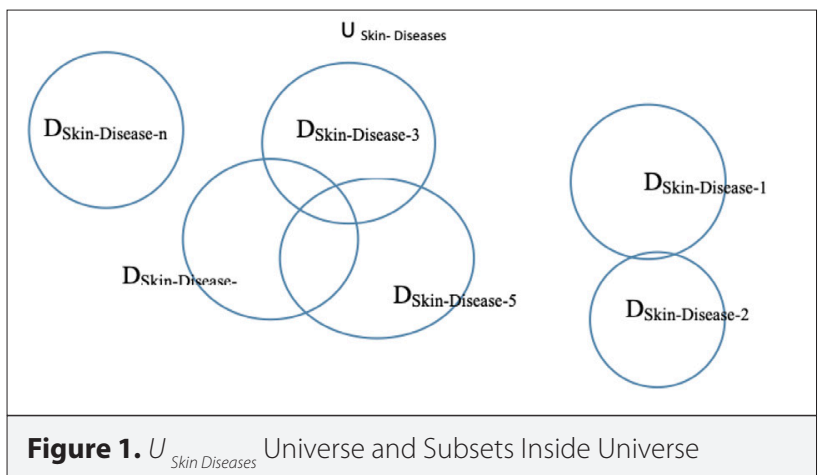

Inside the $U_{\text {Skin- Diseases }}$ one subset, lets call as “ $D$ ", may contain the individuals having dermatologic diseases. Subset $D$, can have another random set, " $X$ " which may contain correlated variables $x$, with set " $D$ ". Where $X$, for example, is a set that is composed of the members whom owns the disease " $D$ ", then we can look for the probability $P(X)$, of an individual to be a member of the set X. Pre-diagnosis of dermatological diseases (as other diseases), could be done by identifying the combination of some physical symptoms designated by; $\left\{D_{1}, D_{2}, \ldots, D_{N}\right\}$

$$
D=\sum_{i=1}^{N} D_{N} \text {, here } N \text { shows the total number of symptoms of disease } D
$$

As mentioned before; patients having psoriasis, seborrheic dermatitis, rosacea or chronic dermatitis can complain similar symptoms such as erythema, scaling, definite borders and itching; that makes the diagnose difficult for family practitioners or primary care physician. This kind of basic system designs especially can support help to family practitioners or primary care physician to prevent misdiagnose. Therefore can also help to improve quality of patient's life. In our previous works [17], we proved that endocrinal diseases such as acromegaly, prolactinoma and Cushing's disease can be described by means of a stationary linear stochastic system (LSS) which is described by

$\mathrm{y}=\sum_{\mathrm{k}=1}^{\mathrm{N}} \mathrm{w}_{\mathrm{k}} \mathrm{x}_{\mathrm{k}}$ 
Here $w_{k}$ are the weight coefficients which works on the random inputs $x_{k}$ 's over a linear operator as specified in [15] and they are predicted employing a training set. In this work we establish the model to predict if one has the illness or what is the illness that the individual has and the possibility of having the disease. To do this we built up 4 seperate training set that contains various number of patients data who certainly has psoriasis, seborrheic dermatitis, chronic dermatitis disease and rosacea respectively Figure 2 .

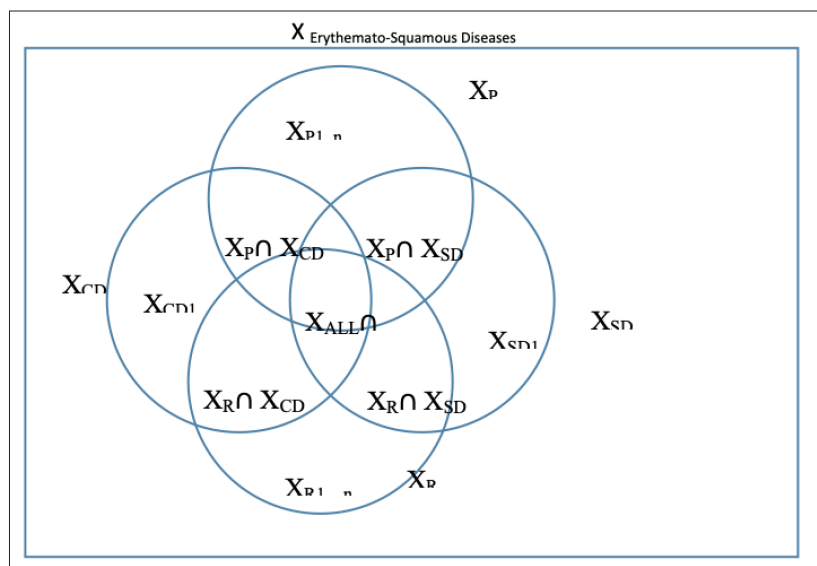

Figure 2. $X$ Universe (Subset of $U_{S}$ and Set Relations Inside Universe

\section{Steps Followed In Designing Algorithm 1: Building Sets, Determination of Attributes and Estimation of Weight Co- efficients}

Step 1: Ask an expert about frequent disease syndromes and develop an multiple choice anamnesis guide to obtain clinical data from patients whom certainly has the diagnose of the psoriasis, seborrheic dermatitis, chronic dermatitis disease and rosacea respectively. Also obtain more data from patients to include the coefficients of personal complaints. Step 2: Classify the obtained clinical data base filled with anamnesis informations to extract complete set of attributes.

Step 3: Using the clinical data base construct a sample set $\mathrm{X}_{\mathrm{s}}$. Step 4: Develop a module to decompose the sample set $X_{S}$ into its attribute sets $\left\{X_{s} \cap X_{n}\right\}, n=1, . . N$.

Step 5: Generate the training set $\mathrm{X}_{\mathrm{T}}$ with $\sum_{n}^{N} n_{k}$ members.

Step 6: Estimate and store the LSS parameters for future use self tests, $w_{k}=\frac{n_{k}}{N_{T}}$

Step 7: Combine all steps in sequential manner under training block.

11 clinical and 22 histopathological data concerning four dermal diseases have been used in our study. Every property was graded with values of 012 or 3 . The training set for psoriasis, $\mathrm{X}_{\mathrm{p}}$ was formed with 100 patients who certainly had psoriasis. Every property was associated with a set and that set ex- hibits the severity of any property related to the patient with psoriasis. For example, set $\mathrm{X}_{1}$ exhibits the property of dermal itchiness in psoriasis was graded 2.3 over 3 . Total number of members calculated by adding of all severity grades is found to be $N_{T}=29.98$. The event set, grades of severity and weight coefficients are given in Table 1. training set for seborrheic dermatitis is established with 55 patients who certainly had seborrheic dermatitis. Total number of members of seborrheic dermatitis was found to be $\mathrm{N}_{\mathrm{T}}=18.22$. Calculated severities for seborrheic dermatitis disease and weight coefficients are given in Table 1. training set for chronic dermatitis disease and $X_{R}$ training set for rosacea were established with 45 patients who were diagnosed. Calculated severities for chronic dermatitis disease and rosacea disease and weight coefficients are given in Table 1.

\section{Application of Linear Stochastic System (LSS) Model}

Aim of the self-test module is to enable a random user to enter attribute scores such as 1 and 0 . Here 1 entrance means that individual has that complaint, 0 entrance to anamnesis means has no such a complaint. Clinical anamnesis form is designed in digital era with only choices "Have" which will be saved as 1 in database, "Dont Have" which will be saved as 0 in database.

\section{Steps Followed In Designing Algorithm 2: Obtaining Self- Test Mode}

Step 1: Design the clinical anamnesis

Step 2: Classify the obtained clinical data base filled with anamnesis informations to extract complete set of attributes. Step 3: Using the clinical data base construct a sample set $\mathrm{X}_{\mathrm{s}}$. Step 4: Develop a module to decompose the sample set $\mathrm{X}_{\mathrm{s}}$ into its attribute sets $\left\{X_{s} \cap X_{n}\right\}, n=1, \ldots N$.

Step 5: Generate the training set $X_{\mathrm{T}}$ with $\sum_{n}^{N} n_{k}$ members.

Step 6: Estimate and store the LSS parameters for future use self tests, $w_{k}=\frac{n_{k}}{N_{T}}$

Step 7: Combine all steps in sequential manner under training block.

Self-tests for psoriasis, seborrheic dermatitis, chronic dermatitis and rosacea diseases were conducted using the weight coefficients from Table 2. It was checked if the patient formerly diagnosed had the properties given in Table 2, if the property was present $P\left(X_{k}\right)=1$; if not $P\left(X_{k}\right)=0$. Thus, every $P\left(X_{k}\right)$ value was calculated, added and a value between zero and one was reached. It was concluded that the related patient had the disease having the highest score value. In the test conducted for psoriasis the results were: $P\left(X_{P_{\text {soriasis }}}\right)=0.95, P\left(X_{\text {s.Dermatitis }}\right)=0.72$, $P\left(X_{\text {C.Dermatitis }}\right)=0.77 P\left(X_{\text {Rosacea }}\right)=0.73$. According to these results, the patient was supposed to have psoriasis $95 \%$, chronic dermatitis 77\%, Rosacea 73\% and Seborrheic dermatitis 72\%. As the highest score was reached for psoriasis, the patient may be diagnosed for psoriasis. The results are given in Table 2 in detail. 
Table 1. Weight coefficients of the four dermal diseases

\begin{tabular}{|c|c|c|c|c|c|}
\hline Event Sets & Clinical and Histopathological Properties & Psoriasis & $\begin{array}{l}\text { Seborrheic } \\
\text { Dermatitis }\end{array}$ & $\begin{array}{c}\text { Chronic } \\
\text { Dermatitis }\end{array}$ & Rosacea \\
\hline$X 1$ & Erythema & 0.076718 & 0.124751 & 0.086667 & 0.122449 \\
\hline$x 2$ & Scaling & 0.073382 & 0.112774 & 0.061333 & 0.097668 \\
\hline X3 & Definite Borders & 0.070380 & 0.048902 & 0.053333 & 0.075802 \\
\hline$x 4$ & Itching & 0.030354 & 0.094810 & 0.114667 & 0.030612 \\
\hline$\times 5$ & Koebner Phenomenon & 0.022682 & 0.001996 & 0.000000 & 0.080175 \\
\hline$x 6$ & Polygonal Papules & 0.000000 & 0.000000 & 0.000000 & 0.000000 \\
\hline$x 7$ & Follicular Papules & 0.001334 & 0.000998 & 0.016000 & 0.000000 \\
\hline $\mathrm{x} 8$ & Oral Mucosal Involvement & 0.000000 & 0.000000 & 0.000000 & 0.000000 \\
\hline$x 9$ & Knee and Elbow Involvement & 0.052702 & 0002994 & 0.002667 & 0.000000 \\
\hline$\times 10$ & Scalp Involvement & 0.049700 & 0.006986 & 0.000000 & 0.000000 \\
\hline $\mathrm{X} 11$ & Family History & 0.030020 & 0.005988 & 0.000000 & 0.000000 \\
\hline $\mathrm{X} 12$ & Melanin Incontinence & 0.000000 & 0.000000 & 0.000000 & 0.000000 \\
\hline$x 13$ & Eosinophils in the Infiltrate & 0.001334 & 0.025948 & 0.004000 & 0.002915 \\
\hline $\mathrm{X} 14$ & PNL Infiltrate & 0.039026 & 0.063872 & 0.000000 & 0.007289 \\
\hline$\times 15$ & Fibrosis of the Papillary Dermis & 0.000000 & 0.000000 & 0.137333 & 0.000000 \\
\hline $\mathrm{X} 16$ & Exocytosis & 0.010007 & 0.118762 & 0.042667 & 0.138484 \\
\hline $\mathrm{X} 17$ & Acanthosis & 0.069380 & 0.095808 & 0.136000 & 0.094752 \\
\hline $\mathrm{X} 18$ & Hyperkeratosis & 0.028019 & 0.009980 & 0.048000 & 0.021866 \\
\hline$\times 19$ & Parakeratosis & 0.065710 & 0.058882 & 0.049333 & 0.053936 \\
\hline$x 20$ & Clubbing of the Rete Ridges & 0.069380 & 0.000000 & 0.005333 & 0.000000 \\
\hline$x 21$ & Elongation of the Rete Ridges & 0.074716 & 0.009980 & 0.109333 & 0.000000 \\
\hline$x 22$ & Thinning of the Suprapapillary Epidermis & 0.067045 & 0.000998 & 0.001333 & 0.000000 \\
\hline$x 23$ & Spongiform Pustule & 0.031021 & 0.009980 & 0.001333 & 0.000000 \\
\hline$x 24$ & Munro Microabcess & 0.036358 & 0.000000 & 0.000000 & 0.001458 \\
\hline X25 & Focal Hypergranulosis & 0.000000 & 0.000000 & 0.000000 & 0.000000 \\
\hline$x 26$ & Disappearance of the Granular Layer & 0.035690 & 0.000000 & 0.000000 & 0.024781 \\
\hline$x 27$ & Vacuolisation and Damage of Basal Layer & 0.000334 & 0.000000 & 0.000000 & 0.000000 \\
\hline$x 28$ & Spongiosis & 0.000000 & 0.116766 & 0.021333 & 0.131195 \\
\hline$x 29$ & Saw-tooth Appearance of Retes & 0.000000 & 0.000000 & 0.000000 & 0.001458 \\
\hline X30 & Follicular Horn Plug & 0.000000 & 0.000998 & 0.001333 & 0.000000 \\
\hline X31 & Perifollicular Parakeratosis & 0.000000 & 0.000998 & 0.000000 & 0.000000 \\
\hline$\times 32$ & Inflammatory Monoluclear Inflitrate & 0.063709 & 0.084830 & 0.106667 & 0.115160 \\
\hline \multirow[t]{2}{*}{ X33 } & Band-like Infiltrate & 0.001001 & 0.001996 & 0.001333 & 0.000000 \\
\hline & & $W_{s}=1$ & $W_{S}=1$ & $W_{s}=1$ & $W_{s}=1$ \\
\hline
\end{tabular}


Table 2. Self-test results of psoriasis disease

\begin{tabular}{|c|c|c|c|c|c|c|}
\hline Event Sets & Clinical and Histopathological Properties & Psoriasis & $\begin{array}{l}\text { Seborrheic } \\
\text { Dermatitis }\end{array}$ & $\begin{array}{c}\text { Chronic } \\
\text { Dermatitis }\end{array}$ & Rosacea & $\mathbf{P}\left(\mathbf{X}_{\mathbf{k}}\right)$ \\
\hline$x 1$ & Erythema & 0.076718 & 0.124751 & 0.086667 & 0.122449 & 1 \\
\hline$x 2$ & Scaling & 0.073382 & 0.112774 & 0.061333 & 0.097668 & 1 \\
\hline X3 & Definite Borders & 0.070380 & 0.048902 & 0.053333 & 0.075802 & 1 \\
\hline$x 4$ & Itching & 0.030354 & 0.094810 & 0.114667 & 0.030612 & 1 \\
\hline$\times 5$ & Koebner Phenomenon & 0.022682 & 0.001996 & 0.000000 & 0.080175 & 1 \\
\hline$x 6$ & Polygonal Papules & 0 & 0 & 0 & 0 & 0 \\
\hline$x 7$ & Follicular Papules & 0 & 0 & 0 & 0 & 0 \\
\hline$x 8$ & Oral Mucosal Involvement & 0 & 0 & 0 & 0 & 0 \\
\hline X9 & Knee and Elbow Involvement & 0.052702 & 0.002994 & 0.002667 & 0.000000 & 1 \\
\hline$\times 10$ & Scalp Involvement & 0.049700 & 0.006986 & 0.000000 & 0.000000 & 1 \\
\hline $\mathrm{X} 11$ & Family History & 0.030020 & 0.005988 & 0.000000 & 0.000000 & 1 \\
\hline$\times 12$ & Melanin Incontinence & 0 & 0 & 0.000000 & 0 & 0 \\
\hline$\times 13$ & Eosinophils in the Infiltrate & 0 & 0 & 0 & 0 & 0 \\
\hline $\mathrm{X} 14$ & PNL Infiltrate & 0.039026 & 0.063872 & 0.000000 & 0.007289 & 1 \\
\hline$\times 15$ & Fibrosis of the Papillary Dermis & 0 & 0 & 0 & 0 & 0 \\
\hline X16 & Exocytosis & 0 & 0 & 0 & 0 & 0 \\
\hline $\mathrm{X} 17$ & Acanthosis & 0.069380 & 0.095808 & 0.136000 & 0.094752 & 1 \\
\hline $\mathrm{X} 18$ & Hyperkeratosis & 0.028019 & 0.009980 & 0.048000 & 0.021866 & 1 \\
\hline X19 & Parakeratosis & 0.065710 & 0.058882 & 0.049333 & 0.053936 & 1 \\
\hline$\times 20$ & Clubbing of the Rete Ridges & 0.069380 & 0.000000 & 0.005333 & 0.000000 & 1 \\
\hline$x 21$ & Elongation of the Rete Ridges & 0.074716 & 0.009980 & 0.109333 & 0.000000 & 1 \\
\hline$x 22$ & Thinning of the Suprapapillary Epidermis & 0.067045 & 0.000998 & 0.001333 & 0.000000 & 1 \\
\hline $\mathrm{X} 23$ & Spongiform Pustule & 0 & 0 & 0 & 0 & 0 \\
\hline$x 24$ & Munro Microabcess & 0.036358 & 0.000000 & 0.000000 & 0.001458 & 1 \\
\hline X25 & Focal Hypergranulosis & 0 & 0 & 0 & 0 & 0 \\
\hline$\times 26$ & Disappearance of the Granular Layer & 0.035690 & 0.000000 & 0.000000 & 0.024781 & 1 \\
\hline$x 27$ & Vacuolisation and Damage of Basal Layer & 0 & 0 & 0 & 0 & 0 \\
\hline$x 28$ & Spongiosis & 0 & 0 & 0 & 0 & 0 \\
\hline X29 & Saw-tooth Appearance of Retes & 0 & 0 & 0 & 0 & 0 \\
\hline$\times 30$ & Follicular Horn Plug & 0 & 0 & 0 & 0 & 0 \\
\hline X31 & Perifollicular Parakeratosis & 0 & 0 & 0 & 0 & 0 \\
\hline X32 & Inflammatory Monoluclear Inflitrate & 0.063709 & 0.084830 & 0.106667 & 0.115160 & 1 \\
\hline \multirow[t]{2}{*}{ X33 } & Band-like Infiltrate & 0 & 0 & 0 & 0 & 0 \\
\hline & & $W_{s}=0.95$ & $W_{s}=0.72$ & $W_{s}=0.77$ & $W_{s}=0.73$ & \\
\hline
\end{tabular}


Table 3. Self-test results of seborrheic dermatitis disease

\begin{tabular}{|c|c|c|c|c|c|c|}
\hline Event Sets & Clinical and Histopathological Properties & Psoriasis & $\begin{array}{l}\text { Seborrheic } \\
\text { Dermatitis }\end{array}$ & $\begin{array}{c}\text { Chronic } \\
\text { Dermatitis }\end{array}$ & Rosacea & $\mathbf{P}\left(\mathbf{X}_{\mathbf{k}}\right)$ \\
\hline$X 1$ & Erythema & 0.076718 & 0.124751 & 0.086667 & 0.122449 & 1 \\
\hline$x 2$ & Scaling & 0.073382 & 0.112774 & 0.061333 & 0.097668 & 1 \\
\hline$x 3$ & Definite Borders & 0.070380 & 0.048902 & 0.053333 & 0.075802 & 1 \\
\hline$x 4$ & Itching & 0.030354 & 0.094810 & 0.114667 & 0.030612 & 1 \\
\hline$\times 5$ & Koebner Phenomenon & 0 & 0 & 0 & 0 & 0 \\
\hline$x 6$ & Polygonal Papules & 0 & 0 & 0 & 0 & 0 \\
\hline X7 & Follicular Papules & 0 & 0 & 0 & 0 & 0 \\
\hline $\mathrm{x} 8$ & Oral Mucosal Involvement & 0 & 0 & 0 & 0 & 0 \\
\hline X9 & Knee and Elbow Involvement & 0.052702 & 0.002994 & 0.002667 & 0.000000 & 1 \\
\hline$\times 10$ & Scalp Involvement & 0 & 0 & 0 & 0 & 0 \\
\hline $\mathrm{X} 11$ & Family History & 0.030020 & 0.005988 & 0.000000 & 0.000000 & 1 \\
\hline $\mathrm{X} 12$ & Melanin Incontinence & 0 & 0 & 0 & 0 & 0 \\
\hline $\mathrm{X} 13$ & Eosinophils in the Infiltrate & 0 & 0 & 0 & 0 & 0 \\
\hline $\mathrm{x} 14$ & PNL Infiltrate & 0.039026 & 0.063872 & 0.000000 & 0.007289 & 1 \\
\hline$\times 15$ & Fibrosis of the Papillary Dermis & 0 & 0 & 0 & 0 & 0 \\
\hline $\mathrm{X} 16$ & Exocytosis & 0.010007 & 0.118762 & 0.042667 & 0.138484 & 1 \\
\hline$\times 17$ & Acanthosis & 0.069380 & 0.095808 & 0.136000 & 0.094752 & 1 \\
\hline X18 & Hyperkeratosis & 0 & 0 & 0 & 0 & 0 \\
\hline X19 & Parakeratosis & 0.065710 & 0.058882 & 0.049333 & 0.053936 & 1 \\
\hline$x 20$ & Clubbing of the Rete Ridges & 0 & 0 & 0 & 0 & 0 \\
\hline$x 21$ & Elongation of the Rete Ridges & 0 & 0 & 0 & 0 & 0 \\
\hline$x 22$ & Thinning of the Suprapapillary Epidermis & 0 & 0 & 0 & 0 & 0 \\
\hline$x 23$ & Spongiform Pustule & 0 & 0 & 0 & 0 & 0 \\
\hline$x 24$ & Munro Microabcess & 0 & 0 & 0 & 0 & 0 \\
\hline$x 25$ & Focal Hypergranulosis & 0 & 0 & 0 & 0 & 0 \\
\hline$x 26$ & Disappearance of the Granular Layer & 0 & 0 & 0 & 0 & 0 \\
\hline$x 27$ & Vacuolisation and Damage of Basal Layer & 0 & 0 & 0 & 0 & 0 \\
\hline$x 28$ & Spongiosis & 0.000000 & 0.116766 & 0.021333 & 0.131195 & 1 \\
\hline$\times 29$ & Saw-tooth Appearance of Retes & 0 & 0 & 0 & 0 & 0 \\
\hline$\times 30$ & Follicular Horn Plug & 0 & 0 & 0 & 0 & 0 \\
\hline$\times 31$ & Perifollicular Parakeratosis & 0 & 0 & 0 & 0 & 0 \\
\hline X32 & Inflammatory Monoluclear Inflitrate & 0.063709 & 0.084830 & 0.106667 & 0.115160 & 1 \\
\hline \multirow[t]{2}{*}{ X33 } & Band-like Infiltrate & 0 & 0 & 0 & 0 & 0 \\
\hline & & $W_{s}=0.58$ & $W_{s}=0.93$ & $W_{s}=0.67$ & $W_{s}=0.87$ & \\
\hline
\end{tabular}


Table 4. Self-test results of chronic dermatitis disease

\begin{tabular}{|c|c|c|c|c|c|c|}
\hline Event Sets & Clinical and Histopathological Properties & Psoriasis & $\begin{array}{l}\text { Seborrheic } \\
\text { Dermatitis }\end{array}$ & $\begin{array}{c}\text { Chronic } \\
\text { Dermatitis }\end{array}$ & Rosacea & $\mathbf{P}\left(\mathbf{X}_{\mathbf{k}}\right)$ \\
\hline $\mathrm{X} 1$ & Erythema & 0.076718 & 0.124751 & 0.086667 & 0.122449 & 1 \\
\hline$x 2$ & Scaling & 0 & 0 & 0 & 0 & 0 \\
\hline$x 3$ & Definite Borders & 0.070380 & 0.048902 & 0.053333 & 0.075802 & 1 \\
\hline$x 4$ & Itching & 0.030354 & 0.094810 & 0.114667 & 0.030612 & 1 \\
\hline$\times 5$ & Koebner Phenomenon & 0 & 0 & 0 & 0 & 0 \\
\hline$x 6$ & Polygonal Papules & 0 & 0 & 0 & 0 & 0 \\
\hline X7 & Follicular Papules & 0 & 0 & 0 & 0 & 0 \\
\hline$x 8$ & Oral Mucosal Involvement & 0 & 0 & 0 & 0 & 0 \\
\hline$x 9$ & Knee and Elbow Involvement & 0 & 0 & 0 & 0 & 0 \\
\hline $\mathrm{X} 10$ & Scalp Involvement & 0 & 0 & 0 & 0 & 0 \\
\hline $\mathrm{X} 11$ & Family History & 0 & 0 & 0 & 0 & 0 \\
\hline $\mathrm{X} 12$ & Melanin Incontinence & 0 & 0 & 0 & 0 & 0 \\
\hline $\mathrm{X} 13$ & Eosinophils in the Infiltrate & 0 & 0 & 0 & 0 & 0 \\
\hline $\mathrm{X} 14$ & PNL Infiltrate & 0 & 0 & 0 & 0 & 0 \\
\hline X15 & Fibrosis of the Papillary Dermis & 0.000000 & 0.000000 & 0.137333 & 0.000000 & 1 \\
\hline X16 & Exocytosis & 0.010007 & 0.118762 & 0.042667 & 0.138484 & 1 \\
\hline X17 & Acanthosis & 0.069380 & 0.095808 & 0.136000 & 0.094752 & 1 \\
\hline $\mathrm{X} 18$ & Hyperkeratosis & 0 & 0 & 0 & 0 & 0 \\
\hline X19 & Parakeratosis & 0.065710 & 0.058882 & 0.049333 & 0.053936 & 1 \\
\hline X20 & Clubbing of the Rete Ridges & 0 & 0 & 0 & 0 & 0 \\
\hline$\times 21$ & Elongation of the Rete Ridges & 0.074716 & 0.009980 & 0.109333 & 0.000000 & 1 \\
\hline$\times 22$ & Thinning of the Suprapapillary Epidermis & 0 & 0 & 0 & 0 & 0 \\
\hline$X 23$ & Spongiform Pustule & 0 & 0 & 0 & 0 & 0 \\
\hline$\times 24$ & Munro Microabcess & 0 & 0 & 0 & 0 & 0 \\
\hline$\times 25$ & Focal Hypergranulosis & 0 & 0 & 0 & 0 & 0 \\
\hline X26 & Disappearance of the Granular Layer & 0 & 0 & 0 & 0 & 0 \\
\hline$\times 27$ & Vacuolisation and Damage of Basal Layer & 0 & 0 & 0 & 0 & 0 \\
\hline X28 & Spongiosis & 0 & 0 & 0 & 0 & 0 \\
\hline X29 & Saw-tooth Appearance of Retes & 0 & 0 & 0 & 0 & 0 \\
\hline X30 & Follicular Horn Plug & 0 & 0 & 0 & 0 & 0 \\
\hline X31 & Perifollicular Parakeratosis & 0 & 0 & 0 & 0 & 0 \\
\hline X32 & Inflammatory Monoluclear Inflitrate & 0.063709 & 0.084830 & 0.106667 & 0.115160 & 1 \\
\hline \multirow[t]{2}{*}{ X33 } & Band-like Infiltrate & 0 & 0 & 0 & 0 & 0 \\
\hline & & $W_{s}=0.46$ & $W_{s}=0.63$ & $W_{S}=0.84$ & $W_{s}=0.63$ & \\
\hline
\end{tabular}


Table 5. Self-test results of Rosacea disease

\begin{tabular}{|c|c|c|c|c|c|c|}
\hline Event Sets & Clinical and Histopathological Properties & Psoriasis & $\begin{array}{l}\text { Seborrheic } \\
\text { Dermatitis }\end{array}$ & $\begin{array}{c}\text { Chronic } \\
\text { Dermatitis }\end{array}$ & Rosacea & $\mathbf{P}\left(\mathbf{X}_{\mathbf{k}}\right)$ \\
\hline$X 1$ & Erythema & 0.076718 & 0.124751 & 0.086667 & 0.122449 & 1 \\
\hline$x 2$ & Scaling & 0.073382 & 0.112774 & 0.061333 & 0.097668 & 1 \\
\hline X3 & Definite Borders & 0.070380 & 0.048902 & 0.053333 & 0.075802 & 1 \\
\hline$x 4$ & Itching & 0.030354 & 0.094810 & 0.114667 & 0.030612 & 1 \\
\hline$\times 5$ & Koebner Phenomenon & 0.022682 & 0.001996 & 0.000000 & 0.080175 & 1 \\
\hline$x 6$ & Polygonal Papules & 0 & 0 & 0 & 0 & 0 \\
\hline$x 7$ & Follicular Papules & 0 & 0 & 0 & 0 & 0 \\
\hline$x 8$ & Oral Mucosal Involvement & 0 & 0 & 0 & 0 & 0 \\
\hline X9 & Knee and Elbow Involvement & 0 & 0 & 0 & 0 & 0 \\
\hline$\times 10$ & Scalp Involvement & 0 & 0 & 0 & 0 & 0 \\
\hline X11 & Family History & 0 & 0 & 0 & 0 & 0 \\
\hline$\times 12$ & Melanin Incontinence & 0 & 0 & 0 & 0 & 0 \\
\hline$\times 13$ & Eosinophils in the Infiltrate & 0 & 0 & 0 & 0 & 0 \\
\hline X14 & PNL Infiltrate & 0 & 0 & 0 & 0 & 0 \\
\hline X15 & Fibrosis of the Papillary Dermis & 0 & 0 & 0 & 0 & 0 \\
\hline X16 & Exocytosis & 0.010007 & 0.118762 & 0.042667 & 0.138484 & 1 \\
\hline $\mathrm{X} 17$ & Acanthosis & 0.069380 & 0.095808 & 0.136000 & 0.094752 & 1 \\
\hline $\mathrm{X} 18$ & Hyperkeratosis & 0 & 0 & 0 & 0 & 0 \\
\hline X19 & Parakeratosis & 0 & 0 & 0 & 0 & 0 \\
\hline$\times 20$ & Clubbing of the Rete Ridges & 0 & 0 & 0 & 0 & 0 \\
\hline$x 21$ & Elongation of the Rete Ridges & 0 & 0 & 0 & 0 & 0 \\
\hline$x 22$ & Thinning of the Suprapapillary Epidermis & 0 & 0 & 0 & 0 & 0 \\
\hline$x 23$ & Spongiform Pustule & 0 & 0 & 0 & 0 & 0 \\
\hline$x 24$ & Munro Microabcess & 0 & 0 & 0 & 0 & 0 \\
\hline$\times 25$ & Focal Hypergranulosis & 0 & 0 & 0 & 0 & 0 \\
\hline$x 26$ & Disappearance of the Granular Layer & 0 & 0 & 0 & 0 & 0 \\
\hline$x 27$ & Vacuolisation and Damage of Basal Layer & 0 & 0 & 0 & 0 & 0 \\
\hline$x 28$ & Spongiosis & 0.000000 & 0.116766 & 0.021333 & 0.131195 & 1 \\
\hline$\times 29$ & Saw-tooth Appearance of Retes & 0 & 0.000000 & 0.000000 & 0 & 0 \\
\hline X30 & Follicular Horn Plug & 0 & 0.000998 & 0.001333 & 0 & 0 \\
\hline X31 & Perifollicular Parakeratosis & 0 & 0.000998 & 0.000000 & 0 & 0 \\
\hline$\times 32$ & Inflammatory Monoluclear Inflitrate & 0.063709 & 0.084830 & 0.106667 & 0.115160 & 1 \\
\hline \multirow[t]{2}{*}{ X33 } & Band-like Infiltrate & 0 & 0 & 0 & 0 & 0 \\
\hline & & $W_{s}=0.42$ & $W_{S}=0.80$ & $W_{s}=0.62$ & $W_{s}=0.89$ & \\
\hline
\end{tabular}


The results of the self test conducted for seborrheic dermatitis are given in Table 3. The results of the calculations were: $P\left(X_{\text {S.Der- }}\right.$ matitis $)=0.93, P\left(X_{\text {Rosacea }}\right)=0.87, P\left(X_{\text {C.Dermatitis }}\right)=0.67$ and $P\left(X_{P_{\text {soriasis }}}\right)=0.58$. The patient was diagnosed to have seborrheic dermatitis as the results indicated the highest probability rate for this disease.

The results of the self test conducted for chronic dermatitis are given in Table 4 and the results indicated that the patient had chronic dermatitis as this disease showed the highest probability rate. The results of the calculations were: $P\left(X_{\text {C.Dermatitis }}\right)=0.84$, $P\left(X_{\text {S.Dermatitis }}\right)=0.63, P\left(X_{\text {Rosacea }}\right)=0.63$, and $P\left(X_{\text {Psoriasis }}\right)=0.46$.

The results of the self test conducted for Rosacea are given in Table 5 and the results indicated that the patient had Rosacea as this disease showed the highest probability rate. The results of the calculations were: $P\left(X_{\text {Rosacea }}\right)=0.89, P\left(X_{\text {C.Dermatitis }}\right)=0.62, P\left(X_{\text {s. }}\right.$ Dermatitis $)=0.80$, and $P\left(X_{\text {Psoriasis }}\right)=0.42$.

\section{Conclusion}

Typical clinical prediction and prevention models provides the probability of an illness occurance or such as reccurence, stage and grade. With respect to knowledge lying behind, system can also support clinician in diagnose and treatment. In this work, we present an expert system called Symptom Based Clinical Decision Support Tool (SBCDST) for early diagnosis of erythemato-squamous diseases incorporating decisions made by Bayesian classification algorithm. Attributes are generated from the typical sign and symptoms of disorder. Based on our clinical results, tool yields $72 \%, 93 \%, 89 \%$ and $95 \%$ correct decisions on the Psoriasis, Seborrheic Dermatitis, Rosacea and Chronic dermatitis diseases respectively. In this kind of systems two major issues; usefulness and accuracy need to be addressed: In our presented study SBCDST addresses both major issues for family practitioners to prevent misdiagnose and mis-use of drugs. System also contains information and eutrophy suggestion pages for the patients having complaints similar to all four erythemato-squamous disease and provides guidance to the expert.

Peer-review: Externally peer-reviewed.

Conflict of Interest: The authors have no conflicts of interest to declare.

Financial Disclosure: The authors declared that this study has received no financial support.

\section{References}

1. E.D. Übeylı, I Güler, "Automatic detection of erythemato-squamous diseases using adaptive neuro-fuzzy inference systems", Comput Biol Med, vol. 35, no. 5, pp. 421-433, 2005. [CrossRef]
2. H.A. Guvenir, G. Demiro z, N. IIlter, "Learning differential diagnosis of erythemato-squamous diseases using voting feature intervals", Artif Intell Med, vol. 13, pp. 147-165, 1998. [CrossRef]

3. R. O. Duda, P. E. Hart, D. G. Stork, "Pattern classification", John Wiley \& Sons, 2012.

4. K. Fukunaga, "Introduction to statistical pattern recognition", Academic press, 2013.

5. S.P. Raychaudhuri, E. M. Farber, "The prevalence of psoriasis in the world", J Eur Acad Dermatol Venereol, vol. 15, no.1, pp. 16-17, Jan, 2001. [CrossRef]

6. L. Sagi, H. Trau, "The koebner phenomenon”, Clin Dermatol, vol. 29, no.2, pp. 231-236, Apr, 2011. [CrossRef]

7. A. A. Pettey , R. Balkrishnan, S. R. Rapp , A. B. Fleischer , S. R. Feldman, "Patients with palmoplantar psoriasis have more physical disability and discomfort than patients with other forms of psoriasis: implications for clinical practice", J Am Acad Dermatol vol. 49. No. 2, pp. 271-275., Aug, 2003. [CrossRef]

8. S. P. Raychaudhuri, E. M. Farber, "The prevalence of psoriasis in the world." J Eur Acad Dermatol Venereol vol. 15, no. 1, pp. 16-17, Jan, 2001. [CrossRef]

9. C. O. McCall, "Psoriasis: Clinical features and pathology", AJSP: Reviews \& Reports, vol. 16, no. 1, pp. 2-9, 2011. [CrossRef]

10. A. K. Gupta, R. Bluhm, "Seborrheic dermatitis", J Eur Acad Dermatol Venereol, vol. 18, no.1, pp. 13-26, Jan, 2004. [CrossRef]

11. R. A. Schwartz., A. C. Janusz, C. K. Janniger, "Seborrheic dermatitis: an overview", Am Fam Physician, vol. 74, no.1, pp. 125-130, Jul, 2006.

12. P. Milde, E. Hölzle, N. Neumann, P. Lehmann, U. Trautvetter, G. Plewig, "Chronic actinic dermatitis. Concept and case examples", Hautarzt, vol. 42, vol.10, pp. 617-622, Oct, 1991.

13. i.ü. Cerrahpaşa Tıp Fakültesi Sürekli Tıp Eğitimi Etkinlikleri Cilt Hastalıkları ve Yara Bakımı Sempozyumu 18-19 Ekim 2001, İstanbul, s. 57-59 Sürekli Tıp Eğitimi Etkinlikleri i.Ü. Cerrahpaşa Tıp Fakültesi Sürekli Tıp Eğitimi Komisyonu Atopik Dermatit Prof. Dr. Oya Oğuz 10. http://turkdermatoloji.org.tr/public/media/hasta_ bilgilendirme/Roza.pdf Access date: 12.10.2016.

14. Roza Hastalığı Bilgilendirme Broşürü, Available from: http://turkdermatoloji.org.tr/public/media/hasta_bilgilendirme/Roza.pdf.

15. E. Karakoç Aydıner, S. Barış, C. Özdemir, "Atopic Dermatitis and Diagnostic Tests", Turkiye Klinikleri J Dermatol-Special Topics vol. 4, no. 2, pp. 8-12, 2011.

16. F. S. Larsen, J. M. Hanifin, "Epidemiology of atopic dermatitis", Immunol Allergy Clin North Am vol. 22, no. 1, pp. 1-24, 2002. [CrossRef]

17. I. Z. Gökbay, S. L. Karaman, S. Yarman, B. S. Yarman, "An Intelligent Decision Support Tool for Early Diagnosis of Functional Pituitary Adenomas", TWMS J App Eng Math vol. 5, no. 2, pp. 169-187, 2015.

18. H. A. Güvenir, G. Demiröz, N. Ilter, "Learning differential diagnosis of erythemato-squamous diseases using voting feature intervals", Artif Intell Med, vol. 13, no. 3, pp.147-165, Jul, 1998.

19. A. N. Ünal, B. S. B. Yarman, "Milli Güç Unsurlarının Belirlenmesinde Siber Uzay Faktörü", in $7^{\text {th }}$ International Conference on Information Security and Cryptology, İstanbul, 17-18 Oct, 2014. 

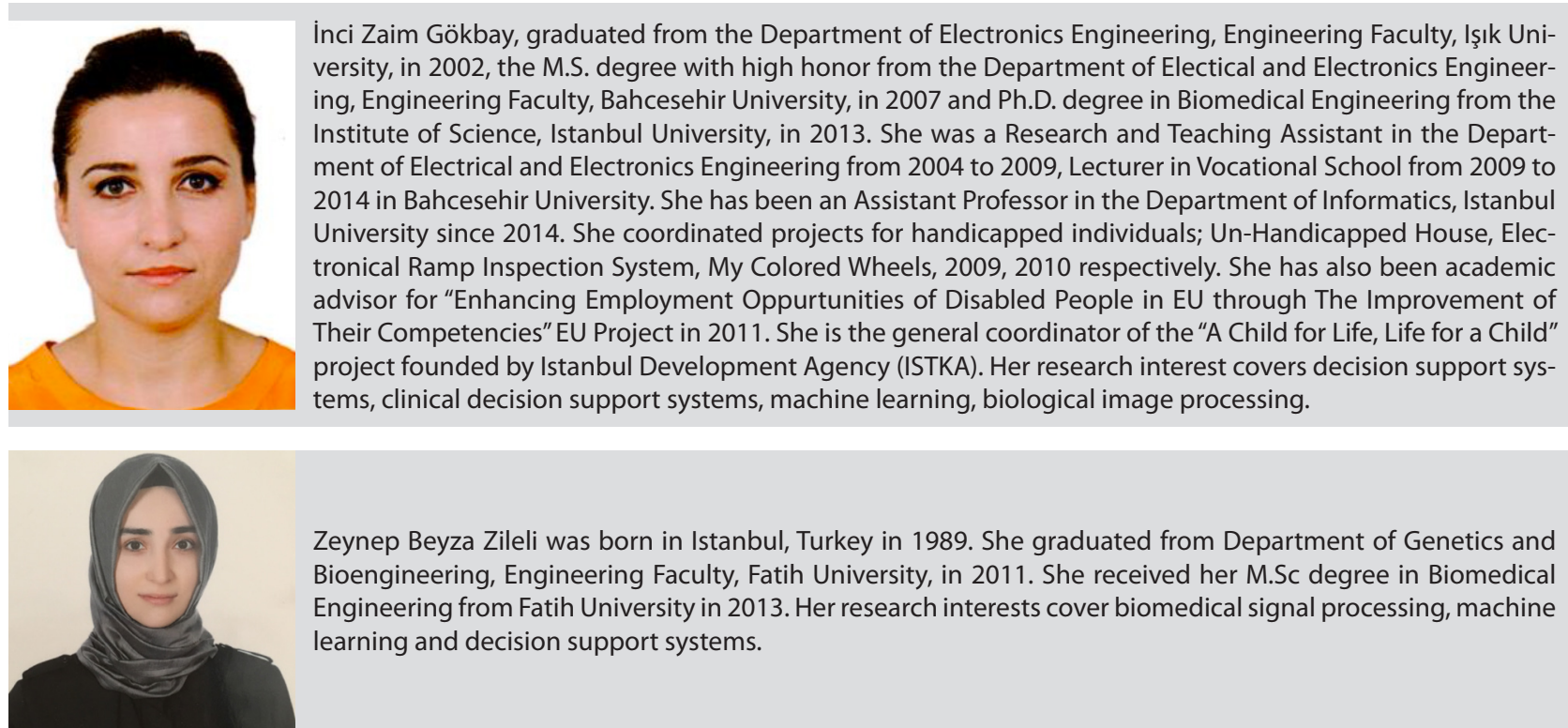

Zeynep Beyza Zileli was born in Istanbul, Turkey in 1989. She graduated from Department of Genetics and Bioengineering, Engineering Faculty, Fatih University, in 2011. She received her M.Sc degree in Biomedical Engineering from Fatih University in 2013. Her research interests cover biomedical signal processing, machine learning and decision support systems.

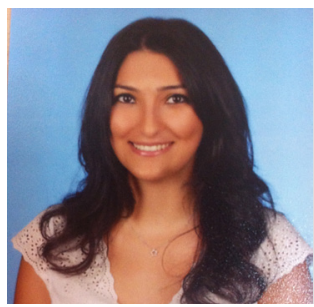

Pelin Sarı was born in Kırklareli,Turkey in 1984. She received her bachelor degree in Biology in 2006 from Marmara University, M.S. degree in Biomedical Engineering in 2010 from Istanbul University, started PhD education in Biomedical Engineering at Istanbul University in 2015 and now she is in the thesis stage.Since 2010 she has been working as an Biomedical Specialist at Istanbul University Cerrahpasa Medical Faculty, Biomedical and Clinical Engineering Unit.

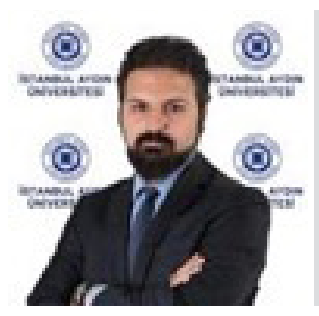

Türker Togay Aksoy is currently working is İstanbul Aydın Üniversity. He is PhD candidate is department of Biomedical Engineering at İstanbul University-Cerrahpaşa. His research interests include biomedical signal processing and robotic control. He has made variety of presentations at national and international congress.

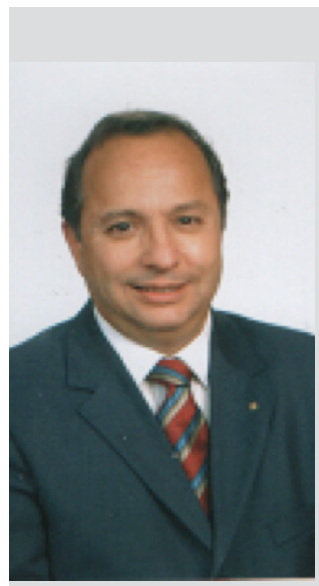

Sıddık Yarman received his BSc Degree from Technical University of Istanbul in 1974; MSc. Degree from Stevens Institute of Technology (1977), Hoboken, N.J., USA, and Ph.D. Degree from Cornell University (1982), Ithaca, NY, USA. He was a Member of Technical Staff at General David Sarnoff Microwave Technology and Research Center, in Princeton, NJ, USA. He served as professor and administrator at various Universities: Anadolu University, Middle East Technical University, Istanbul University, Isik University of Turkey; Ruhr University of Germany, Tokyo Institute of Technology of Japan, Wuhan Technology University of China. He is one of the founders of Savronik Group of Companies and recently serves as the Chairman of the Board of Directors. He was the founding president of Isik University (1996-2004). Currently serves as the Chairman of Board of Trustees. He published numerous papers in the field of Microwave Engineering, Circuit and Systems, Signal Processing, Mathematical Modeling and Decision Making. He has published 4 books: Design of Ultra - Wideband Antenna Matching Networks by Springer (2008), Design of Ultra - Wideband Power Transfer Networks by Wiley (2010), Intelligence Based Decision Making by Nobel Press of Turkey (2014) and He is one of the co-author of the book titled "Broadband Microwave and RF Power Amplifiers" by CRC (November 2015). He holds 4 US and 9 Turkish Patents. He was the recipient of Young Turkish Scientist Award (1986), Technology Award (1987) of Scientific and Research Council of Turkey. He is a member of New York Academy of Science (1994), selected as the Man of the year in Science and Technology of Cambridge Biography (1999). He is a Fellow of IEEE; Alexander Von Humboldt Fellow and Salzburg Fellow of USIS. 